\title{
Integración bosque industria: Una necesidad regional
}

\author{
Freddy Rojas Rodríguez ${ }^{1}$
}

\section{INTRODUCCION}

Mientras los sectores productivos industriales a nivel mundial y regional se disputan los mercados con claras concepciones de competitividad, calidad total y reingeniería, el sector forestal industrial todavía continúa regionalmente discutiendo, reclamando y proponiendo políticas, estrategias y líneas de acción para poder desarrollarse.

Con el fin de poder comprender el sector forestal en su conjunto, es recomendable dividirlo en dos componentes : el sector forestal protector, cuya meta es asegurar la perpetuidad en el uso y manejo de los recursos naturales por la vía de la conservación, y el sector forestal industrial, cuya meta es lograr abastecer por la vía del manejo forestal las necesidades tangibles de productos forestales que la sociedad requiere; este último componente es el objeto de discusión del presente artículo.

\section{Retos regionales en integración bosque- industria}

La región centroamericana y en alguna medida México, enfrenta el reto de transformar y elevar el nivel tecnológico para lograr un desarrollo sostenible del proceso industrial basado en bosques, para lo cual deberá:

\footnotetext{
Desarrollar modelos de auténtica integración del bosque con la industria: no
}

es prudente, estratégico ni recomendable que los esfuerzos por elevar la competitividad del sector productivo forestal conciban el bosque y la industria como dos entes productivos aislados, cuando de ambos depende el uso eficiente de los productos forestales.

- Elevar la capacidad científica y tecnológica de los recursos humanos del sector: desagregar el componente forestal productivo en especialistas en cultivo y manejo de árboles y bosques y especialistas en industria de la madera, fue el común denominador de la región y como resultado de esta acción hoy en día se ha acumulado una experiencia significativa en silvicultura, pero poco se ha avanzado en materia industrial; en síntesis sabemos cultivar y manejar bosques, pero no sabemos qué productos y procesos aplicar a nuestra cosecha de madera. Esta desagregación debe cambiar y el nuevo forestal de la región debe dominar integralmente el proceso.

- Elevar la calidad y competitividad de los centros de producción de materias primas y productos forestales: la región ha producido madera y productos forestales por tradición; pero el reto actual no es sólo producir y comercializar, sino producir con calidad y aprovechar con eficiencia cada producto; máxime cuando las dimensiones, calidades y características están cambiando, pues la silvicultura de plantaciones está entregando un producto desconocido en la industria, el cual no necesariamente se adapta a las capacidades y tradición de la industria forestal establecida regionalmente.

1 Profesor-Investigador y Director del Departamento de Ingeniería Forestal. Instituto Tecnológico de Costa Rica. Tel. (506 ) 551-53-33, Fax ( 506 ) 551-53-48 


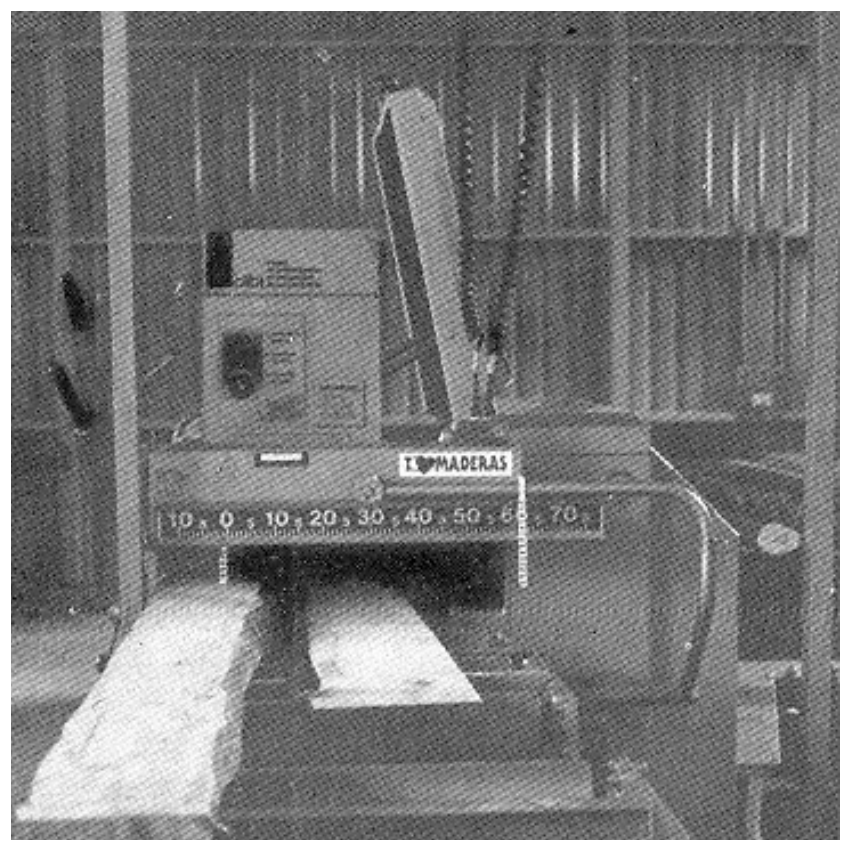

Figura 1. Sierra circular múltiple para procesamiento industrial de diámetros pequeños. CIIBI*, Instituto Tecnológico de Costa Rica.

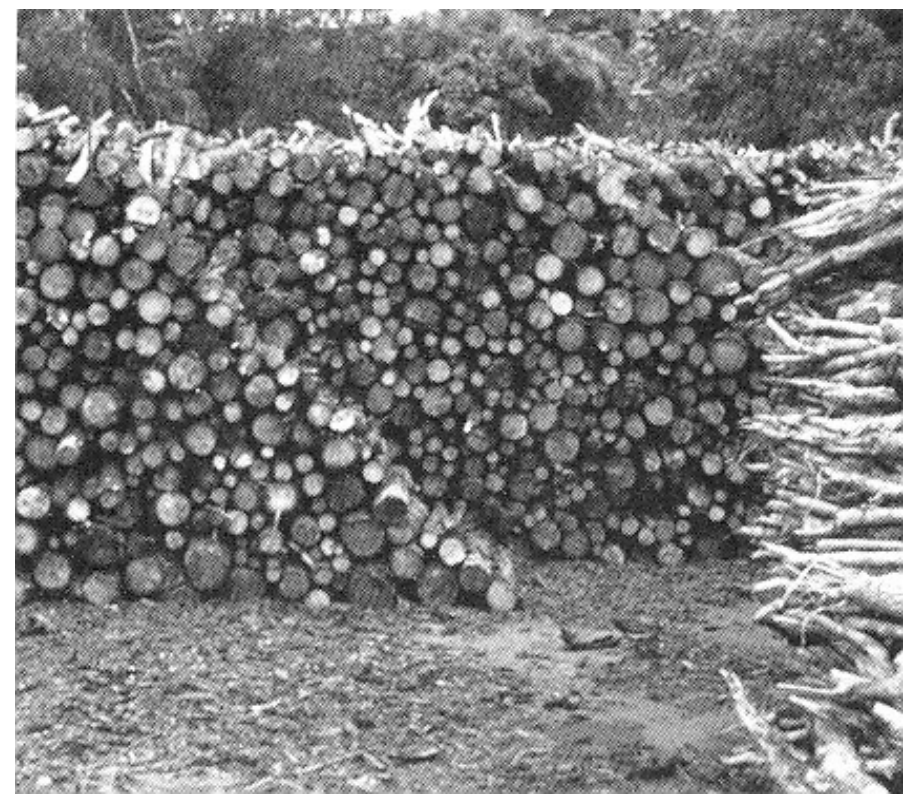

Figura 2. Materia prima de plantaciones forestales para procesamiento industrial
Incursionar en REINGENIERIA FORESTAL es el camino regional: el bosque, la tecnología, el producto y la sociedad así lo demandan.

\section{Aplicación del concepto de integración bosque-industria}

El objetivo meta de la actividad forestal consiste en satisfacer las necesidades $y$ expectativas de bienes y servicios del bosque, beneficiando al mayor número de personas de manera sostenible en el tiempo; por lo tanto, el concepto de INTEGRACION BOSQUE INDUSTRIA fundamentalmente se convierte en una filosofía de trabajo que pretende armonizar la relación BOSQUE SOCIEDAD, mediante una interacción equilibrada de las relaciones socio económicas, ecológicas y tecnológicas involucradas en el proceso productivo forestal integral.

- Socioeconómicas: porque se pretende que todos y cada uno de los sectores del proceso obtengan una retribución justa con relación o aporte de manera sostenida.

- Ecológicas: porque en todo momento, cualquier acción ha de considerar la fragilidad, potencial y limitaciones del ecosistema y el impacto que cualquier medida tendrá sobre el medio ambiente, dentro y fuera del bosque y la industria.

- Tecnológicas: porque el nivel tecnológico a aplicar debe garantizar trabajos de calidad y el máximo grado de eficiencia y eficacia en todas las fases del proceso. 


\section{Principales obstáculos para la integración bosque-industria regional}

- Resistencia al cambio: aún considerando el cambio y las restricciones en la materia prima que llegará a la industria forestal futura, existe una alta dosis de resistencia del industrial sobre el cambio tecnológico requerido, y hay quienes antes de invocar, han decidido salirse del mercado en el futuro, en vez de modernizar su industria.

- Falta de visión integral del proceso: el dueño del bosque natural continúa buscando alternativas económicas diferentes a la actividad forestal, el reforestador muchas veces se preocupa por reforestar y producir madera y el industrial solo se interesa en la materia prima que llega a al industria; pero son escasas las empresas que han decidido incursionar, participar e integrar todo el proceso.

- Defensa de escenarios

tradicionales: el viverista pretende continuar siendo viverista con la filosofía de obtener el máximo de ganancias, pero sin incursionar en tecnologías que mejoren la calidad de las plántulas. El reforestador está interesado en plantar cantidad, al mínimo costo, pero con pocas tecnologías que aumenten la productividad y calidad de las plantaciones. El sivilcultor del bosque natural le interesa el máximo beneficio inmediato de su cosecha y al industrial le interesa materia prima de calidad a bajo costo. El nuevo productor forestal deberá estar claro de incursionar en calidad en cada fase y ver el proceso integralmente.

\section{Avance en integración bosque-industria a nivel regional}

- A nivel de formación de recursos humanos: además de formar silvicultores, ya las escuelas forestales dinámicas y activas en la región han incursionado en la formación de un silvicultor con visión industrial, donde el concepto de calidad, competitividad y visión integral es parte de cada curso. Adicionalmente, el Departamento de Ingeniería Forestal del Instituto Tecnológico de Costa Rica, ha asumido la responsabilidad regional de crear un Programa de Maestría en Integración Bosque-Industria.

- A nivel empresarial: ya el reforestador visionario está instalando su propia industria forestal adaptada al producto y, antes que trozas, de su empresa saldrán muebles, tarimas, puertas, paneles, madera de cuadro para construcción (emplantillados, divisiones, molduras, etc. ).

- A nivel de investigación: la investigación forestal aplicada de la actualidad no se centra meramente en aspectos silviculturales y tecnológicos, hoy día adquiere gran relevancia aspectos relacionados con calidad de productos, propiedades físicas, mecánicas y estructurales, secado, preservación, técnicas de aprovechamiento y comercialización de la nueva materia prima procedente de plantaciones.

En síntesis, nuevos retos ante nuevas materias primas requiere el sector forestal regional del futuro.

\footnotetext{
* El ClIBI es el Centro de Investigación en Integración Bosque-Industria
} 